\title{
Lotus japonicus Contains Two Distinct ENOD40 Genes That Are Expressed in Symbiotic, Nonsymbiotic, and Embryonic Tissues
}

\author{
Emmanouil Flemetakis, ${ }^{1}$ Nektarios Kavroulakis, ${ }^{1}$ Nicolette E. M. Quaedvlieg, ${ }^{2}$ Herman P. Spaink, ${ }^{2}$ \\ Maria Dimou, ${ }^{1}$ Andreas Roussis, ${ }^{2}$ and Panagiotis Katinakis ${ }^{1}$ \\ ${ }^{1}$ Agricultural University of Athens, Department of Agricultural Biotechnology, lera Odos 75, 11855 Athens, \\ Greece; ' ${ }^{2}$ nstitute of Molecular Plant Sciences, Leiden University, Clusius Laboratory, Wassenaarseweg \\ 64, 2333 AL Leiden, The Netherlands \\ Accepted 18 May 2000.
}

\begin{abstract}
ENOD40, an early nodulin gene, has been postulated to play a significant role in legume root nodule ontogenesis. We have isolated two distinct ENOD40 genes from Lotus japonicus. The transcribed regions of the two ENOD40 genes share $65 \%$ homology, while the two promoters showed no significant homology. Both transcripts encode a putative dodecapeptide similar to that identified in other legumes forming determinate nodules. Both ENOD40 genes are coordinately expressed following inoculation of roots with Mesorhizobium loti or treatment with purified Nod factors. In the former case, mRNA accumulation could be detected up to 10 days following inoculation while in the latter case the accumulation was transient. High levels of both ENOD40 gene transcripts were found in nonsymbiotic tissues such as stems, fully developed flowers, green seed pods, and hypocotyls. A relatively lower level of both transcripts was observed in leaves, roots, and cotyledons. In situ hybridization studies revealed that, in mature nodules, transcripts of both ENOD40 genes accumulate in the nodule vascular system; additionally, in young seed pods strong signal is observed in the ovule, particularly in the phloem and epithelium, as well as in globular stage embryos.
\end{abstract}

Additional keywords: nodule organogenesis, symbiosis.

A group of soil bacteria that are collectively called rhizobia can cause the development of root nodules on their leguminous host plants. The developmental program of nodule initiation is triggered by signal molecules exchanged between the two symbionts, resulting in a complex temporal and spatial expression of several plant genes. Genes induced early during the symbiosis are defined as early nodulins (ENOD). Several lines of evidence suggest that early nodulin genes may play a

Corresponding author: P. Katinakis; Agricultural University of Athens, Department of Agricultural Biotechnology, Iera Odos 75, 11855 Athens, Greece; E-mail: bmbi2kap@ auadec.aua.gr

Current address of Nicolette E. M. Quaedvlieg: Keygene N.V., Agrobusiness Park 90, PO Box 216, 6700 AE Wageningen, The Netherlands.

Nucleotide sequences have been submitted to the EMBL database as accession nos. AJ271787 (LjENOD40-1) and AJ271788 ( $L j$ ENOD40-2). role in mediating rhizobial invasion and nodule organogenesis (Mylona et al. 1995). A number of early nodulin cDNA clones have been isolated and characterized, but the function of the encoded proteins still remains unknown. Among the early nodulins, ENOD40 is one of the most rapidly induced during the process of nodule organogenesis in both determinate and indeterminate nodule-forming legumes (Kouchi and Hata 1993; Yang et al. 1993; Crespi et al. 1994). The ENOD40 gene is first expressed, in response to rhizobial inoculation, in the root pericycle and subsequently in the dividing cortical cells. In mature, determinate root nodules, ENOD40 transcripts are detected in the pericycle of the vascular bundles (Kouchi and Hata 1993; Yang et al. 1993). A similar spatial pattern of expression is also observed during the ontogeny of indeterminate nodules (Asad et al. 1994; Crespi et al. 1994; Matvienko et al. 1995). Expression of ENOD40 has been reported in non-symbiotic tissues, such as stems (Kouchi and Hata 1993; Yang et al. 1993; Asad et al. 1994), lateral and adventitious root primordia (Papadopoulou et al. 1996) and leaf and stipule primordia (Frang and Hirsch 1998; Corich et al. 1998). ENOD40 gene homologues have also been identified in the nonlegumes tobacco (Matvienko et al. 1996) and rice (Kouchi et al. 1999). Expression analysis studies revealed that ENOD40 transcripts were detected only in the early developmental stages of stem vascular bundles of rice (Kouchi et al. 1999).

In a number of legumes, transcription of the ENOD40 gene could be induced in root tissues in response to purified Nod factors (Minami et al. 1996), cytokinin (van Rhijn et al. 1997), and chitin pentamers (Minami et al. 1996), and during arbuscular mycorrhizae infection (van Rhijn et al. 1997). ENOD40 transcripts were also found in spontaneous nodules (Crespi et al. 1994) and in empty nodules induced by mutant bacteria (Yang et al. 1993; Asad et al. 1994; Crespi et al. 1994).

Results obtained with transgenic Medicago sativa suggest that ENOD40 may be involved in the initiation of nodule formation by triggering cortical cell divisions (Charon et al. 1997). M. sativa embryos over-expressing ENOD40 developed into teratomas, whereas expression of an antisense ENOD40 construct in $M$. sativa explants resulted in arrest of callus growth and loss of embryo formation (Crespi et al. 1994). Moreover, over-expression of ENOD40 in transgenic 
Medicago truncatula plants accelerates nodulation upon inoculation with Sinorhizobium meliloti (Charon et al. 1999).

The ENOD40 transcripts are characterized by the absence of a long open reading frame (ORF), which led to the hypothesis that ENOD40 genes code for an untranslated RNA. However, comparison of the potential ORFs of the ENOD40 gene transcripts identified so far revealed the presence of a small ORF coding for a highly conserved, small peptide 10 to 13 amino acids long (Vijn et al. 1995b; Kouchi et al. 1999).

In this study, we demonstrate that there are two distinct ENOD40 genes present in Lotus japonicus that are expressed in both symbiotic and nonsymbiotic tissues. In situ hybridization studies show that ENOD40 transcripts are localized in the vascular system of nodular and ovular tissues as well as in the globular stage embryos.

\section{RESULTS}

\section{L. japonicus contains two distinct ENOD40 genes.}

Several cDNA clones were isolated from a cDNA library prepared from 21-day-old L. japonicus nodules, with a cloned polymerase chain reaction (PCR) fragment (designated as LjENOD40p) of L. japonicus genomic DNA as a probe. The nucleotide sequence of the identified cDNA clones revealed that they all share identical sequences and showed high homology to the soybean ENOD40 genes. The largest cDNA, of $550 \mathrm{bp}$, excluding the polyA tail, was designated as $L j$ ENOD40-1c. To identify the total number of ENOD40 genes, genomic DNA from L. japonicus was digested with EcoRI and/or HindIII and subjected to Southern blot analysis. The data obtained revealed the presence of two EcoRI hybridizing bands of about 2.4 and $3.2 \mathrm{~kb}$, respectively (data not shown).

To isolate and characterize the two putative ENOD40 genes, several genomic clones were isolated by screening an L. japonicus genomic library. Southern blot analysis of genomic $L$. japonicus DNA and representative genomic lambda clones indicated that the latter contained either of both hybridizing EcoRI fragments from the plant genome (data not shown). Nucleotide sequence analysis of both EcoRI fragments obtained from the lambda phages (Fig. 1A) revealed that the 2.4-kb EcoRI fragment contained sequences identical to the $L j$ ENOD40-1c cDNA. In contrast, the genomic 3.2-kb EcoRI fragment (Fig. 1A) contained sequences that are homologous but not identical to LjENOD40-1c. Regions of the second ENOD40 gene (designated as LjENOD40-2) that exhibited low homology with the respective regions of LjENOD40-1c were amplified, cloned, named $L j$ ENOD40-2S, and used as a probe to screen a cDNA library prepared from 9day-old L. japonicus roots inoculated with Mesorhizobium loti. Several cDNA clones were identified and their nucleotide sequence was determined. Aside from variation in length, the nucleotide sequence of all the isolated cDNA clones was identical to that of the LjENOD40-2 clone. The cDNA with the largest insert was designated as $L j$ ENOD40-2c. The transcription start of both ENOD40 genes was determined by 5rapid amplification of cDNA ends (5' RACE). Two distinct $5^{\prime}$ ends were identified for $L j$ ENOD40-1 transcripts while only one was identified for LjENOD40-2 (Fig. 1B). Comparison of the nucleotide sequences of the two L. japonicus ENOD40 genes demonstrated that they share only 65\% identity (Fig.
1B). It can be noted that a 55-bp insertion is present in the LjENOD40-2 gene. A 75-bp insertion has also been detected in the alfalfa ENOD40 gene (Crespi et al. 1994). Sequence comparison revealed that the proximal sequences of the two promoter regions showed no significant sequence homology (Fig. 1B).

The percentage of nucleotide sequence similarity of the two L. japonicus ENOD40 genes, compared with those reported in other legumes, indicates that, within the legume family, two major ENOD40 groups have evolved, which can be designated as group I and group II (Fig. 2A). The legumes forming determinate nodules are clustered in group I and those forming indeterminate ones in group II. Interestingly, within group I, the two L. japonicus ENOD40 genes belong to different clades.

It has been demonstrated that all known ENOD40 genes in legumes contain two conserved regions, named regions I and II. Region I contains a small ORF encoding a peptide of 12 or 13 amino acids in determinate or indeterminate nodule forming legumes, respectively (Vijn et al. 1995b). Analysis of the nucleotide sequence of the two L. japonicus cDNA clones demonstrated that both contained the proposed regions I and II. In both ENOD40 gene transcripts, region I encodes for the proposed conserved 12 amino acids peptide (Figs. 1B and $2 B$ ). It should be noted that the pI values of the predicted peptides differ significantly. Interestingly, the $\mathrm{pI}$ value of the peptide encoded by the LjENOD40-1c clone appears to be similar to that of Sesbania rostrata and common bean, whereas the pI value of the peptide encoded by the $L j$ ENOD40-2c clone is similar to that of pea and alfalfa (Fig. 2B).

\section{Both ENOD40 genes are induced by $M$. loti and purified LCOs.}

The accumulation of both ENOD40 genes transcripts was examined after inoculation with $M$. loti or treatment with purified lipo-chitin oligosaccharides (LCOs). Accumulation of ENOD40 transcripts was examined up to 10 days post inoculation with $M$. loti and the two ENOD40 transcripts showed the same dynamics of expression (Fig. 3A). Treatment with purified $M$. loti LCOs induced, at 5 days post treatment, similar dynamics of accumulation of both ENOD40 genes, at levels comparable to those observed 5 days after inoculation with bacteria. However, at 10 days post treatment, the accumulation of transcripts was markedly reduced to basal levels (Fig. 3A). It should also be pointed out that no visible, nodulelike structures were observed 10 days after the treatment of the young seedlings with LCOs, in contrast with what was previously reported in the case of Lotus preslii (Lopez-Lara et al. 1995).

\section{Expression of ENOD40 genes in nonsymbiotic tissues of L. japonicus.}

Several groups have reported that in legumes the ENOD40 gene, in addition to its expression in symbiotic organs, is also expressed in nonsymbiotic organs (Crespi et al. 1994; Asad et al. 1994; Papadopoulou et al. 1996; Corich et al. 1998). Thus, it was of interest to investigate whether both ENOD40 genes are also expressed in various plant organs. To test this, a semiquantitative reverse transcription (RT)-PCR analysis was employed. The results indicated that the mRNAs isolated from mature nodules, hypocotyls, and young stems contained the highest levels of both ENOD40 gene transcripts (Fig. 3B). 


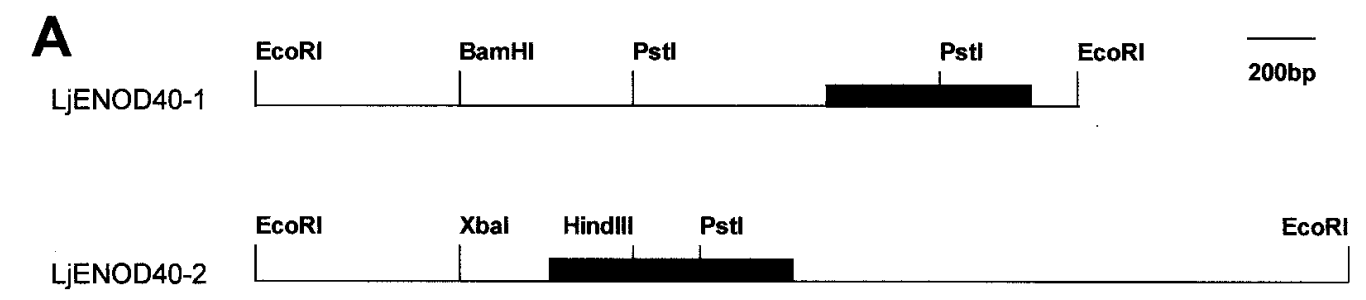

B

\begin{tabular}{|c|c|}
\hline jENOD $40-2$ & 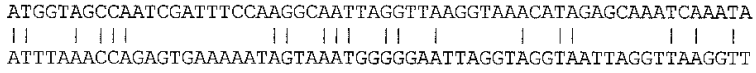 \\
\hline jENOD40-1 & 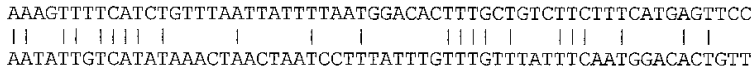 \\
\hline jENOD40-1 & 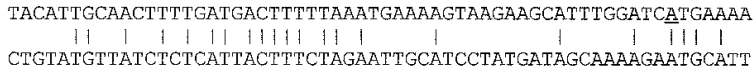 \\
\hline jENOD40-1 & 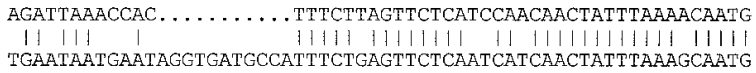 \\
\hline jENOD40-1 & 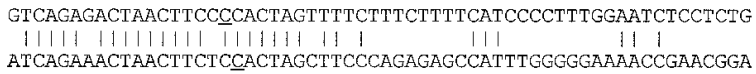 \\
\hline jENOD4 0-1 & 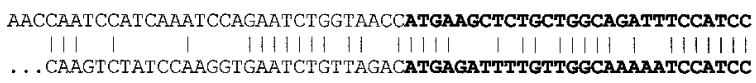 \\
\hline JENOD 40-2 & 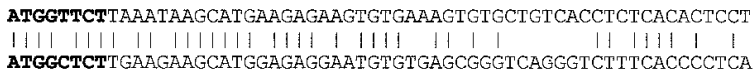 \\
\hline $\begin{array}{l}\text { jENOD40-1 } \\
\text { jENOD40-2 }\end{array}$ & 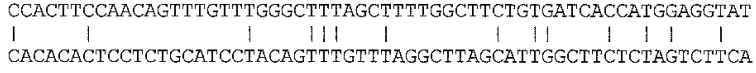 \\
\hline jENOD $40-1$ & 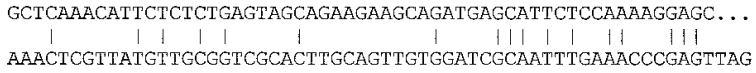 \\
\hline jENOD40-1 & 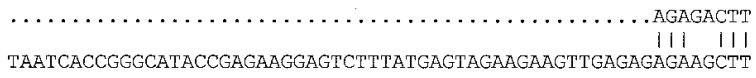 \\
\hline jENOD4 $0-1$ & 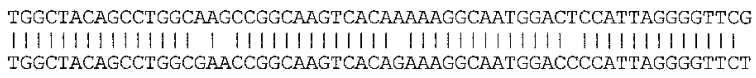 \\
\hline ¿ JENOD40-1 & 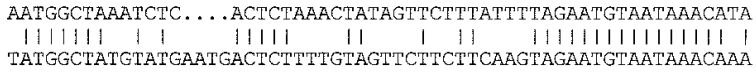 \\
\hline LjENOD40-1 & 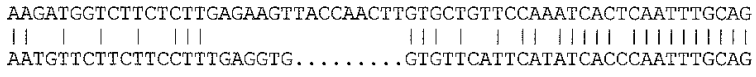 \\
\hline jENOD 40-2 & 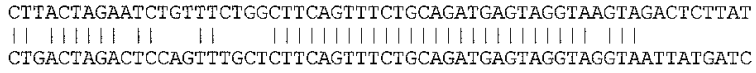 \\
\hline ENOD $40-2$ & 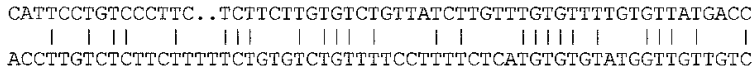 \\
\hline Lj ENOD 40-1 & 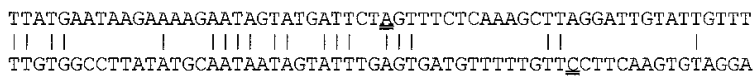 \\
\hline ¿JENOD & $\begin{array}{l}\text { AGAAARGCTTCAGAAT } \\
\text { I IIII } \\
\text { TTGTGTTGTAGAAG }\end{array}$ \\
\hline
\end{tabular}

Fig. 1. Structure of Lotus japonicus ENOD40 genes. A, Restriction maps of the cloned EcoRI fragments that hybridize to LjENOD40-1c and $L j$ ENOD40-2c. Shaded blocks indicate transcribed regions. B, Nucleotide sequences of transcribed regions and $5^{\prime}$ end proximal regions of both $L$. japonicus ENOD40 genes. The $5^{\prime}$ end of the mRNAs was determined by 5-rapid amplification of cDNA ends (5' RACE)-polymerase chain reaction (PCR) and is underlined. Double underlines indicate polyadenylation sites. Region I in both ENOD40 genes is indicated by bold. 
Furthermore, high levels of both transcripts were present in mRNA prepared from fully developed flowers and green seed pods (Fig. 3B). In contrast, relatively lower levels of both transcripts were detected in roots and germinated cotyledons, whereas in leaves the expression of both ENOD40 genes was hardly detectable (Fig. 3B).

\section{Spatial localization of ENOD40 gene transcripts.}

The spatial localization of ENOD40 gene transcripts was investigated by an in situ hybridization approach. At 10 days after inoculation with $M$. loti, LjENOD40-1 is highly expressed in the developing vascular bundles (Fig. 4A and B), as was previously reported (Kouchi and Hata 1993; Yang et al.

\section{A}

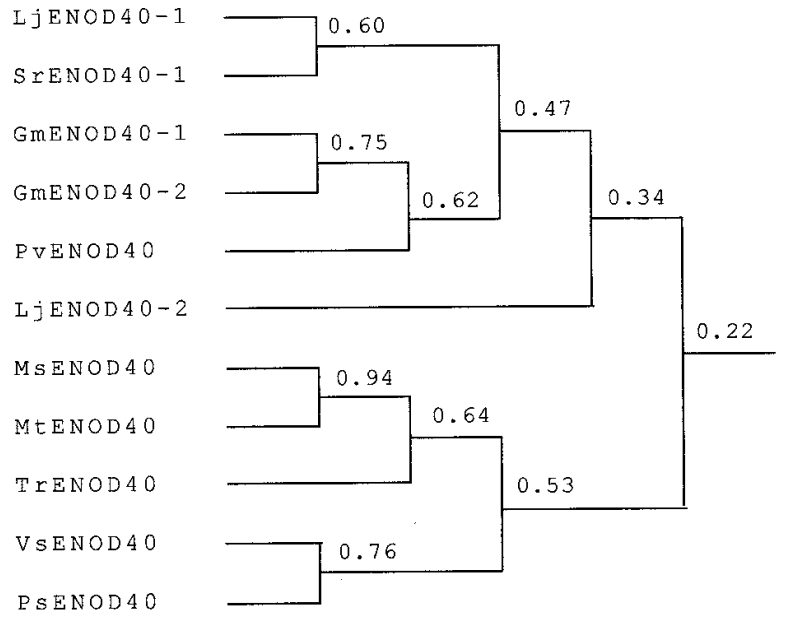

B

\begin{tabular}{|c|c|c|c|}
\hline Clone & Peptide & Length & $\mathrm{CaIC} \cdot p I$ \\
\hline LjENOD 40-1 & MK. LCWQISIHGS & 12 & 8.00 \\
\hline SrENOD 40-1 & $--.----\mathrm{k}-----$ & 12 & 9.31 \\
\hline PVENOD 40 & $--. f---a-----$ & 12 & 8.00 \\
\hline $\mathrm{L} J \mathrm{ENOD} 40-2$ & $-r f .---k-----$ & 12 & 9.50 \\
\hline MSENOD 40 & $--1----k-----$ & 13 & 9.31 \\
\hline VSENOD 40 & $--1----k-----$ & 13 & 9.31 \\
\hline TrENOD 40 & $--1----\mathrm{k}-----$ & 13 & 9.31 \\
\hline PSENOD 40 & $--f----k-----$ & 13 & 9.31 \\
\hline MtENOD 40 & $--1---$ ek $--\cdots--$ & 13 & 7.78 \\
\hline GMENOD 40-1. & -elcwqt.----- & 12 & 5.22 \\
\hline GIENOD $40-2$ & - elcwlt.t---- & 12 & 5.22 \\
\hline NEENOD 40 & -qwdea...--- & 10 & 4.35 \\
\hline OSENOD 40 & - edewleha.--- & 12 & 4.39 \\
\hline ODENOD 40 & -edewleha.--- & 12 & 4.39 \\
\hline
\end{tabular}

Fig. 2. Phylogenetic relationship of ENOD40 genes from various legumes and comparison of putative encoded oligopeptides. A, Phylogenetic tree based on ENOD40 cDNA sequences from various leguminous plants. B, Comparison of amino acid sequences encoded by region I of ENOD40 genes from various plants, together with predicted pI values. Plant species and DDBJ, EMBL, and GenBank data base accession nos.: Lj, Lotus japonicus (this work); Gm, Glysine max (a, D13503; b, D13504); Sr, Sesbania rostrata (Y12714); Pv, Phaseolus vulgaris (X86441); Ms, Medicago sativa (X80263); Vs, Vicia sativa (X83683); Tr, Trifolium repens (AJ000268); Ps, Pisum sativum (X81064); Mt, Medicago truncatula (X80264); Nt, Nicotiana tabacum (X98716); Os, Oryza sativa (ABO24054); Ob, Oryza brachyantha (ABO24055).
1993). Interestingly, $L j$ ENOD40-2 gene transcripts showed a similar expression pattern in 10-day-old nodules (Fig. 4C), when clone $L j$ ENOD40-2S was used to transcribe the antisense RNA probe. In 21-day-old nodules, $L j$ ENOD40-1 gene transcripts accumulate in the vascular tissue surrounding the nodule (Fig. 4D and E). Additionally, in green young pods, $L j$ ENOD40-1 is up-regulated in the ovules and very strong hybridization signal is observed in the phloem tissue (Fig. 4F and G) and epithelium cells (Fig. 4F). High expression was also observed at the globular stage embryo (Fig. $4 \mathrm{H}$ ). In the seed pod tissues surrounding the ovule, no hybridization signal above background was detected. As a negative control, sections were hybridized to sense RNA probe transcribed from $L j$ ENOD40-1c clone (Fig. $4 \mathrm{~J}-\mathrm{M}$ ). In this case, no significant hybridization signal was detected.

A

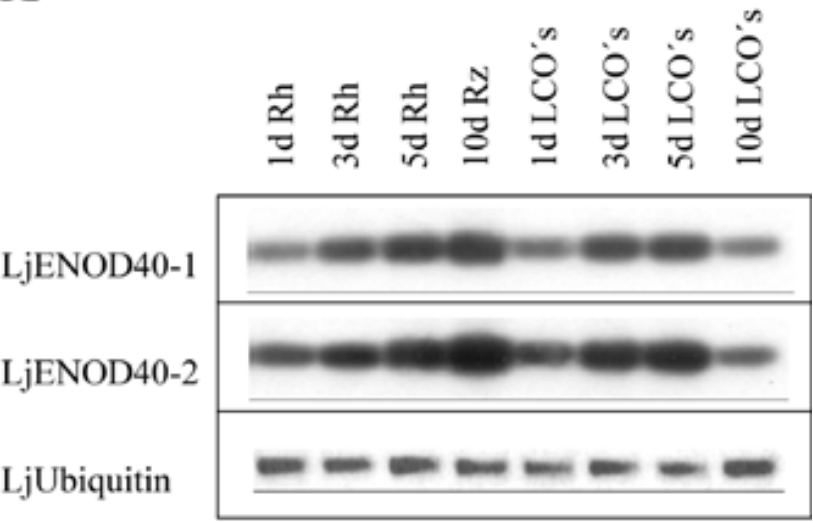

B

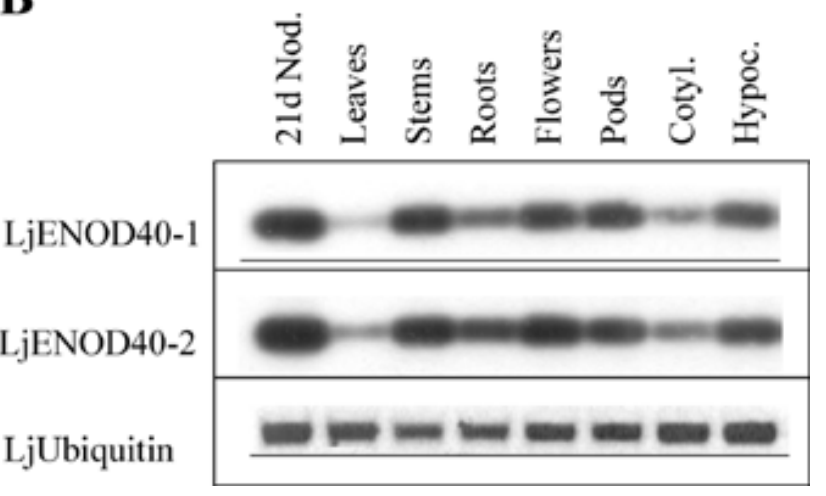

Fig. 3. Accumulation of $L j E N O D 40$ genes transcripts in symbiotic and nonsymbiotic tissues of Lotus japonicus and after treatment with Mesorhizobium loti purified lipo-chitin oligosaccharides (LCOs). Total RNAs from the various tissues were subjected to reverse transcriptionpolymerase chain reaction (RT-PCR) analysis with $L j$ Ubiquitin as internal control. Amplification products were analyzed on $1.5 \%$ agarose gels, blotted to nylon membranes, and probed with LjENOD40-1c and LjENOD40-2c respectively. A, Lanes 1-4, L. japonicus (Gifu B-129) roots $1,3,5$, and 10 days after inoculation with $M$. loti (strain E1R.pMP2112). Lanes 5-8, L. japonicus (Gifu B-129) roots 1, 3, 5, and 10 days after treatment with purified $M$. loti LCOs. B, Lanes 1-8, 21day-old L. japonicus nodules, young leaves, young stems, roots, flowers, green seed pods, germinated cotyledons, and hypocotyls, respectively. 


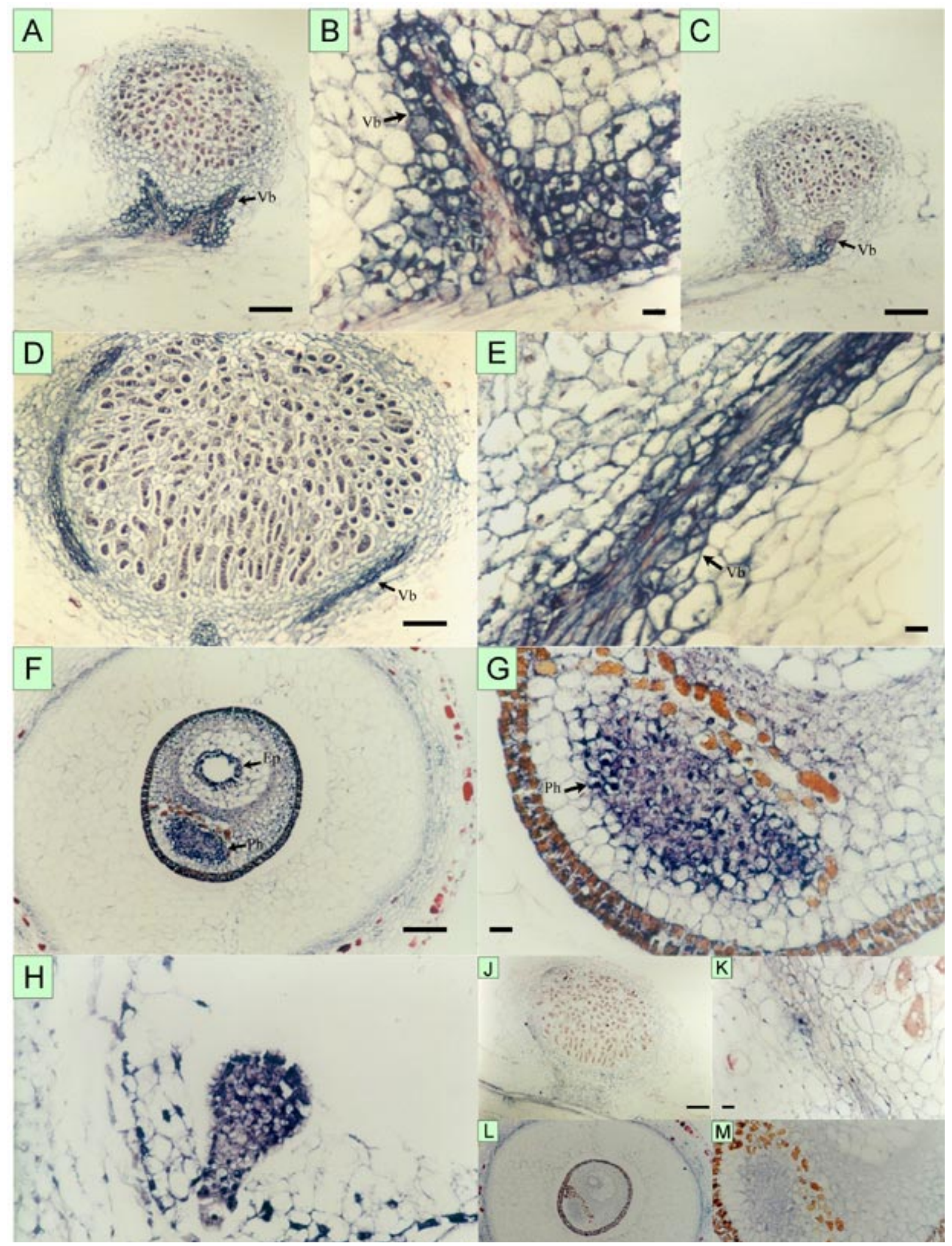

Fig. 4. In situ localization of $L j$ ENOD40 genes transcripts in Lotus japonicus (Gifu B-129) root nodules, young seed pods, and embryos. Hybridization signal is visible as blue-purple precipitate. A and $\mathbf{B}, L j$ ENOD40-1 transcripts in 10-day-old nodules are present in the developing vascular bundles (Vb). $\mathbf{C}$, In nodules of the same age $L j$ ENOD40-2 is also expressed in developing vascular tissue. D and E, In mature 21-day-old nodules $L j E N O D 40-1$ is highly expressed in vascular tissues of nodule. F and $\mathbf{G}$, In young seed pods $L j$ ENOD $40-1$ transcripts are clearly detected in ovule. Elevated level of expression is observed in phloem tissue $(\mathrm{Ph})$ of ovule and epithelium cells (Ep). No visible hybridization signal is detected in pod tissues surrounding ovule. H, Markedly high expression level of $L j$ ENOD40-1 is detected in globular stage embryos. As a negative control, sections of ( $\mathbf{J}$ and $\mathbf{K}) 21$-day-old nodules and ( $\mathbf{L}$ and $\mathbf{M}$ ) young seed pods were hybridized to sense RNA transcribed from $L j$ ENOD40-1c clone. In this case, no significant hybridization signal is visible. Bars $=(\mathbf{A}, \mathbf{C}, \mathbf{D}, \mathbf{F}, \mathbf{J}, \mathbf{L}) 100 \mu \mathrm{m}$ or $(\mathbf{B}, \mathbf{E}, \mathbf{G}, \mathbf{H}, \mathbf{K}, \mathbf{M}) 10 \mu \mathrm{m}$. 


\section{DISCUSSION}

The fact that genomic clones and transcripts for the two distinct ENOD40 genes have been found in the diploid $L$. japonicus, provides strong evidence that there are at least two functional ENOD40 genes. The presence of two ENOD40 genes has also been proposed for the hexaploid soybean (Minami et al. 1996), the tetraploid alfalfa (Frang and Hirsch 1998), and S. rostrata (Corich et al. 1998). However, in the case of alfalfa, the two genes including a large part of the promoter region are identical, while the two soybean ENOD40 genes share a 94\% homology, thus not excluding the possibility that both cases may represent two variants of the same allele. The $S r E N O D 40-1$ is $84.5 \%$ identical to SrENOD40-2. However, SrENOD40-2 appears to lack the sequences coding for the dodecapeptide (Corich et al. 1998). Since the homology of the two L. japonicus ENOD40 cDNA clones is only $65 \%$ it could be argued that a second, distinct ENOD40 gene in other legumes has not yet been found, possibly due to low homology with the identified one.

Molecular, phylogenetic analysis inferred from sequence data of the available ENOD40 genes revealed that ENOD40 genes form two groups among the legumes. An almost identical grouping of legumes was obtained by Doyle et al. (1998), with $r b c L$ sequences. Within group I, the two L. japonicus ENOD40 genes belong to different clades; the LjENOD40-1 gene showed homology of about 78 and $72 \%$ to the soybean ENOD40-1 and common bean ENOD40 genes, respectively, and only about $65 \%$ to the $L j$ ENOD40-2 gene (Fig. 2A). The sequence divergence of the two L. japonicus ENOD40 genes can be partly attributed to insertion sequences, a feature also found in ENOD40 cDNA clones isolated from legumes forming indeterminate nodules (Crespi et al. 1994). These data also suggest that ENOD40 gene duplication events have taken place early in legume evolution.

Both L. japonicus ENOD40 transcripts have the capacity to code the putative 12 amino acid peptide found in legumes that form determinate nodules. Comparison of the putative peptides encoded by ENOD40 genes in different legume and nonlegume plants indicated a diverse calculated $\mathrm{pI}$ value (Fig. 2B). This observation raises the question of whether these peptides may require post-translational modification to be functional and/or that formation of functional complexes with other compounds is necessary for the peptides to be functional in vivo. The sort mating factor peptide, such as the decapeptide from Rhodospiridium toruloids, has been shown to require farnesylation of the C-terminal amino acids to be functional (Rodriguez et al. 1999). Despite the fact that region II is highly conserved at the nucleotide level between the two $L$. japonicus ENOD40 genes, it lacks a conserved typical ORF. This is also the case for all the ENOD40 homologues studied so far (Kouchi et al. 1999), indicating that the translation of this region is not necessary for it to be biological active (Charon et al. 1997).

Expression analysis, with in situ hybridization and semiquantitative RT-PCR, showed that the two L. japonicus ENOD40 genes are co-expressed in the same developmental stage and in the same cell types during nodule organogenesis. Since both genes are induced by purified LCOs, it is plausible to assume that similar signal transduction pathways triggered by the Nod factors might be involved in the activation of equivalent regulatory elements present in the promoters of both genes. The regulatory elements that are required for the induction of both pea ENOD12 (Vijn et al. 1995a) and ENOD40 (Fang and Hirsch 1998) by Nod factors appear to be located within 200 and $600 \mathrm{bp}$, respectively, upstream of the translation start. If identical factors can act on both $L$. japonicus ENOD40 genes, one would expect to find sequence motifs in both genes that are similar. Alternatively, the coordinated induction of the two ENOD40 genes may be mediated by two types of Nod receptors similar to those suggested for alfalfa (Ardourel et al. 1994).

The expression patterns of ENOD40 genes in L. japonicus root nodules followed basically the ones described for soybean (Kouchi and Hata 1993; Yang et al. 1993) and common bean (Papadopoulou et al. 1996). In fully developed nodules, ENOD40 is detected in specific cells of the pericycle of the nodule vascular bundles. Similarly, in L. japonicus embryonic tissues, high levels of expression of ENOD40-1 gene are also observed in the ovules and specifically the strongest signal was observed in the ovule phloem and ovule epithelium cells, as well as in the embryo itself. In rice, expression of the OsENOD40 gene is coupled to specific developmental stages of the stem's lateral vascular bundles (Kouchi et al. 1999). These data, taken together, are in accordance with the hypothesis that ENOD40 gene products mediate the transport of specific metabolites or factors necessary for cell development and growth, as has been proposed before (Papadopoulou et al. 1996). The possible involvement of ENOD40 gene products in organogenetic processes in nonsymbiotic tissues was shown by antisense RNA experiments in $M$. sativa explants that resulted in arrest of callus growth and loss of embryo formation while, in plants over-expressing ENOD40, embryos developed into teratomas (Crespi et al. 1994). The expression of ENOD40 in developing embryos, as well as in ovule tissues, of $L$. japonicus adds further proof to the suggestion that the ENOD40 gene is a plant gene involved in organogenesis (Crespi et al. 1994; Asad et al. 1994; Papadopoulou et al. 1996).

The presence of both ENOD40 gene transcripts in nonsymbiotic tissues of legumes and the occurrence of homologues of ENOD40 in nonleguminous plants such as tobacco (Matvienko et al. 1996) and rice (Kouchi et al. 1999), could mean that the regulatory elements of these genes may be directly activated by factors that are recognizing endogenous LCOlike compounds or other signal molecules that functionally resemble LCOs. This hypothesis is suggested by the biological effects of LCOs on nonlegumes such as carrots (De Jong et al. 1993) or rice (Reddy et al. 1998). It is also possible that the ENOD40 genes are indirectly triggered by Nod factors via an effect on the levels of common plant hormones such as auxin. Evidence for this is provided by the observation that microtargeting of Nod factors or O-acetylated chitin oligomers into the root cortex appears to elicit changes in the characteristics of the root auxin balance during nodule initiation in clover (Mathesius et al. 1998). The information obtained in this study will be very important to further address these hypotheses about the regulation of the ENOD40 genes in the $L$. japonicus system. Analysis of transgenic L. japonicus plants containing a reporter gene whose expression is driven by these promoters would allow further insight into the mechanism of ENOD40 gene induction. For this purpose, constructs of both 
LjENOD40 promoters fused to a gus-gfp gene (Quaedvlieg et al. 1998) have been introduced into L. japonicus with the Agrobacterium tumefaciens system and await further analysis after transgenic seeds have been obtained.

\section{MATERIALS AND METHODS}

\section{Plant material and growth conditions.}

L. japonicus (Gifu B-129) seeds were kindly provided by Jens Stougaard (University of Aarhus, Denmark). All plants were grown in a controlled environment with a $18 \mathrm{~h} / 6 \mathrm{~h}$ day/night cycle, a $22 / 18^{\circ} \mathrm{C}$ day/night regime and $70 \%$ humidity (Handberg and Stougaard 1992). Prior to germination, seeds were scarified by treatment with $\mathrm{H}_{2} \mathrm{SO}_{4}$ for $5 \mathrm{~min}$ and sterilized for 20 min with $2 \% \mathrm{NaOCl}-0.02 \%$ Tween 20 . Seeds were pre-germinated at $18^{\circ} \mathrm{C}$ in the dark for $72 \mathrm{~h}$ and the small plants were grown in Hoagland nutrient solution. For the inoculation with Rhizobium spp., 72-h seedlings were inoculated with a $0.1 \mathrm{OD}_{600}$ suspension of the $M$. loti strain E1R.pMP2112 and the plants were grown in nitrogen-free B\&D nutrient solution (Broughton and Dilworth 1971). Nod factors were isolated from the M. loti strain E1R.pMP2112 by published methods (Lopez-Lara et al. 1995), while the method of application and the concentration of the Nod factors were the same as published for L. preslii (Lopez-Lara et al. 1995).

\section{Isolation of $L j E N O D 40 \mathrm{cDNA}$ and genomic clones.}

For the amplification of ENOD40 homologous sequences from $L$. japonicus, two degenerate primers designated $40 \mathrm{D} 1 \mathrm{~F}$ [5'-ATCCATGGTTCTT(AG)AAGAAG-3'] and 40D2R [5'(GC)C(TC)TTTT(TC)GTGACTTGCCG-3'] were designed with previously published ENOD40 sequences from various leguminous plants. The PCR product was cloned in pBlueScript $\mathrm{KS}^{+}$plasmid vector (Stratagene, La Jolla, CA), resulting in a plasmid named $\mathrm{p} L j$ ENOD40p. The nucleotide sequence of the insert was determined by the dideoxy chain termination method (Sanger et al. 1997).

A $\lambda$ ZAPII L. japonicus polyT-primed cDNA library from 21-day-old nodules and a $\lambda$ fixII $L$. japonicus genomic library was screened by plaque hybridization at $65^{\circ} \mathrm{C}$, with the ${ }^{32} \mathrm{P}$ dCTP-labeled insert of the $L j E N O D 40$ p clone (both libraries were kindly provided by Jens Stougaard). Phage purification and in vitro excision of $\mathrm{pBlueScript} \mathrm{SK}^{+}$plasmids from the $\lambda$ ZAPII library were performed according to standard methods (Stratagene) and the nucleotide sequence was determined as above. The purified phages from the $\lambda$ FIXII genomic library, giving positive hybridization signal were digested with various restriction enzymes blotted and hybridized with the ${ }^{32} \mathrm{P}$ dCTP-labeled insert of the $L j E N O D 40$ p clone used as a probe. The hybridizing EcoRI fragments were subcloned in pBlueScript $\mathrm{KS}^{+}$plasmid vector and the nucleotide sequence was determined.

For the isolation of a cDNA clone of the LgENOD40-2 gene, a specific region from the genomic clone (showing $35 \%$ homology with LgENOD40-1 clone), was amplified by PCR with the oligonucleotides Lg40-2F (5'-GAATGTGTGA GCGGGTCAGG-3') and Lg40-2R (5'-ACTTCTTCTACTC ATAAAGA-3'). The amplification product was cloned in pBlueScript $\mathrm{KS}^{+}$and the clone was designated as $\mathrm{p} L j$ ENOD40-2S. The insert of this clone was labeled with ${ }^{32} \mathrm{P}-$ $\mathrm{dCTP}$ and used as a probe to screen an L. japonicus random- primed $\lambda$ ZAPII cDNA library from 9-day-old roots inoculated with $M$. loti (kindly provided by Jens Stougaard). Phage purification and in vitro excision of the pBlueScript $\mathrm{SK}^{+}$plasmids from the $\lambda$ ZAPII library were performed according to standard methods (Stratagene) and the nucleotide sequence was determined.

\section{Detection of $L j E N O D 40-1$ and $L j E N O D 40-2$ transcripts with an RT-PCR assay.}

All the L. japonicus (Gifu B-129) tissues of interest and young roots inoculated with $M$. loti (strain E1R.pMP2112) or treated with purified $M$. loti Nod factors were harvested and ground in liquid nitrogen. Total RNA was isolated according to Brusslan and Tobin (1992) and quantified by spectrophotometry and agarose gel electrophoresis. Prior to RT-PCR, the total RNA samples were treated with DNase I (Promega, Madison, WI) at $37^{\circ} \mathrm{C}$ for $10 \mathrm{~min}$ for the elimination of contaminating genomic DNA. The Titan One Tube RT-PCR System (Boehringer Mannheim, Mannheim, Germany) was used for the reverse transcription and amplification of ENOD40 transcripts. Three primers were designed: one common primer for both transcripts, named Lj40-C (5'-CCTACTCATCT GCAGAAACTG-3') and two specific primers designated as Lj40-1F (5'-GGAGGTATGCTCAAACAT TC-3') and $L j 40-2 \mathrm{~F}$ (5'-CAAAACTCGTTATGTTGCGG-3'). One hundred nanograms of total RNA treated with DNase I was used for each reaction and the different RNA preparations were normalized by the parallel amplification of the constitutively expressed gene $L j$ Ubiquitin with $L j$ UBQ-F (5'-ATGCAGATCTTTTGT GAAGAC-3') and LjUBQ-R (5'-ACCACCACGGAAGA CGGAG-3') primers. Under our experimental conditions an exponential increase of the ENOD40 RT-PCR products was still observed after 25 cycles $\left(94^{\circ} \mathrm{C} / 1 \mathrm{~min}, 52^{\circ} \mathrm{C} / 1 \mathrm{~min}\right.$, $68^{\circ} \mathrm{C} / 1 \mathrm{~min}$ ), so we performed all the reactions under these conditions to obtain semiquantitative results. The RT-PCR products were analyzed by $1.5 \%$ agarose gel electrophoresis, blotted, and hybridized to $L j$ ENOD40-1 and LjENOD40-2 cDNA probes.

\section{Determination of transcription start with a RACE-PCR assay.}

Total RNA was isolated from 21-day-old nodules as described above and a $5^{\prime}$ RACE-PCR was performed with the SMART 5' RACE kit from Clontech (Westburg, NL). Two gene-specific oligonucleotides were used as primers, one for each ENOD40 transcript. Lj40-1Rc (5'-GAATGTTTGAGCA TACCTCCATGGTG-3') was used for the amplification of LjENOD40-1 specific 5'-end sequences and Lj40-2Rc (5'GGTATCCCGGTGATTACTAACTCGG-3') was used in the case of $L j$ ENOD40-2. The RACE-PCR products were cloned in pBlueScript $\mathrm{KS}^{+}$plasmid vector (Stratagene) and the nucleotide sequence was determined.

\section{In situ hybridization.}

L. japonicus nodules harvested at 10 and 21 days after inoculation of roots with M. loti (strain E1R.pMP2112) and young pods were fixed in $4 \%$ paraformaldehyde supplemented with $0.25 \%$ glutaraldehyde in $10 \mathrm{mM}$ sodium phosphate buffer $\mathrm{pH} 7.4$ for $4 \mathrm{~h}$ in a vacuum aspirator (Papadopoulou et al. 1996). Fixed tissues were dehydrated through ethanol series, embedded in paraffin, and 7- $\mu \mathrm{m}$-thin sections were cut as 
described by Yang et al. (1993). Antisense and sense RNA probes labeled with digoxigenin (DIG)-11-rUTP (Boehringer Mannheim) were transcribed from the LjENOD40-1 and LjENOD40-2S clones with the $\mathrm{T} 3$ and $\mathrm{T} 7$ promoters of pBlueScript $\mathrm{SK}^{+}$. The RNA probes were hybridized to the sections and hybridization signals were visualized with antiDIG antibodies conjugated with alkaline phosphatase (Kouchi and Hata 1993).

\section{ACKNOWLEDGMENTS}

This research was supported by a grant from the EU (FMRX-CT960039) and the Netherlands Organization for scientific research (NWOPIONIER).

\section{LITERATURE CITED}

Ardourel, M., Demon, N., Debelle, F., Mailler. F., de Billy, F., Prome, J.C., Denarie, J., and Truchet, G. 1994. Rhizobium meliloti lipooligosaccharides nodulation factors: Different structural requirements for bacterial entry into target root hair cells and induction of plant symbiotic developmental responses. Plant Cell 6:1357-1374.

Asad, S., Frang, Y., Wycoff, K. L., and Hirsch, A. M. 1994. Isolation and characterization of cDNA and genomic clones of MsENOD40. Transcripts are detected in meristematic cells of alfalfa. Protoplasma 183: $10-23$.

Broughton, W. J., and Dilworth, M. 1971. Control of leghemoglobin synthesis in snake beans. Biochem. J. 125:1075-1080.

Brusslan, J. A., and Tobin, E. M. 1992. Light-independent development regulation of $c a b$ gene expression in Arabidopsis thaliana seedlings. Proc. Natl. Acad. Sci. USA 89:7791-7795.

Charon, C., Carolina, S., Crespi, M., and Kondorosi, A. 1999. Alteration of enod40 expression modifies Medicago truncatula root nodule development induced by Sinorhizobium meliloti. Plant Cell 11:1953-1965.

Charon, C., Jonason, C., Kondorosi, E., Kondorosi, A., and Crespi, M. 1997. enod40 induces dedifferentiation and division of root cortical cells in legumes. Proc. Natl. Acad. Sci. USA 94:8901-8906.

Corich, V., Doodmachtig, S., Lievens, S. L., van Montagu, M., and Holsters, M. 1998. Patterns of ENOD40 gene expression in stem-borne nodules of Sesbania rostrata. Plant Mol. Biol. 37:67-76.

Crespi, M., Jurkevitch, E., Poiter, M., d'Aubenton-Carafa, Y., Petrovics, G., Kondorosi, E., and Kondorosi, A. 1994. Enod40, a gene expressed during nodule organogenesis codes for a non-translatable RNA involved in plant growth. EMBO J. 13:5099-5112.

De Jong, A. J., Heidstra, R., Spaink, H. P., Hartog, M. V., Meljer, E. A., Hendriks, T., Lo Schiavo, F., Terzi, M., Bisseling, T., van Kammen, A., and De Vries, S. 1993. Rhizobium lipo-oligosaccharides rescue a carrot embryo mutant. Plant Cell 5:615-620.

Doyle, J. J. 1998. Phylogenetic perspectives on nodulation: evolving views of plants and symbiotic bacteria. Trends Plant Sci. 3:473-478.

Frang, Y., and Hirsch, A. M. 1998. Studying early nodulin gene ENOD40 expression and induction by nodulating factor and cytokinin in transgenic alfalfa. Plant Physiol. 116:53-68.

Handberg, K., and Stougaard, J. 1992. Lotus japonicus, an autogamous, diploid legume species for classical and molecular genetics. Plant J. 2: 487-496.

Kouchi, H., and Hata, S. 1993. Isolation and characterization of novel nodulins cDNAs representing genes expressed at early stages of soybean nodule development. Mol. Gen. Gen. 238:106-119.
Kouchi, H., Tanake, K.-I., So, R. B., Ladha, J. K., and Reddy, P. M. 1999. Rice ENOD40: Isolation and expression analysis in rice and transgenic soybean root nodules. Plant J. 18:121-129.

Lopez-Lara, I. M., Van den Berg, J. D. J., Thomas-Oates, J. E., Glushka, J., Lugtenberg, B. J. J., and Spaink, H. P. 1995. Structural identification of the lipo-chitin oligosaccharide nodulation signals of Rhizobium loti. Mol. Microbiol. 15:627-638.

Mathesius, U., Schalman, H. R. M., Spaink, H. P., Sautter, C., Rolfe, B. G., and Djordjevic, M. A. 1998. Auxin transport inhibition precedes root nodule formation in white clover roots and is regulated by flavonoids and derivatives of chitin oligosaccharides. Plant J. 14:23-34.

Matvienko, M., vande Sande, K., Pawloski, K., van Kammen, A., and Bisseling, T. 1996. Nicotiana tabacum SR1 contains two ENOD40 homologs. Pages 387-391 in: Biology of Plant Microbe Interactions. G. Stacey, B. Mullin, and P. M. Gresshoff, eds. International Society for Molecular Plant Interactions, St. Paul, MN.

Matvienko, M., vande Sande, K., Pawloski, K., van Kammen, A., Bisseling, T., and Frassen, H. 1995. Comparison of soybean and pea ENOD40 cDNA clones representing genes expressed during both early and late stages of nodule development. Plant Mol. Biol. 26:487493.

Minami, E., Kouchi, H., Cohn, J. R., Jr., Ogawa, T., and Stacey, G. 1996. Expression of the early nodulin ENOD40, in soybean roots in response to various lipo-chitin signal molecules. Plant J. 10:23-32.

Mylona, P., Pawloski, K., and Bisseling, T. 1995. Symbiotic nitrogen fixation. Plant Cell 7:869-885.

Papadopoulou, K., Roussis, A., and Katinakis, P. 1996. Phaseolus ENOD40 is involved in symbiotic and non-symbiotic organogenesis processes: expression during nodule and lateral root development. Plant Mol. Biol. 30:403-417.

Quaedvlieg, N. E. M., Schlaman, H. R. M., Admiraal, P. C., Wijting, S. E., Stougaard, J., and Spaink, H. P. 1998. Fusions between green fluorescent protein and $\beta$-glucuronidase as sensitive and vital bifunctional reporters in plants. Plant Mol. Biol. 38:861-873.

Reddy, P. M., Ladha, J. K., Ramos, M. C., Maillet, F., Hernadez, R. J., Torrizo, L. B., Oliva, N. P., Datta, S. K., and Datta, T. 1998. Rhizobial lipochitooligosaccharide nodulation factors activate expression of the legume early nodulin gene ENOD12 in rice. Plant J. 14:693-702.

Rodriguez, M., Yalovsky, S., and Gruissem, W. 1999. Protein prenylation in plants: Old friends and new targets. Plant Mol. Biol. 39:865870.

Sanger, F., Nicklen, S., and Coulson, A. R. 1977. DNA sequencing with chain-terminating inhibitors. Proc. Natl. Acad. Sci. USA 74:54635467.

van Rhijn, P., Fang, Y., Galili, S., Shaul, O., Atzmon, N., Wininger, S., Eshed, Y., Lum, M., Li, Y., To, V., Fujishige, N., Kapulnik, Y., and Hirsh, A. M. 1997. Expression of early nodulin genes in alfalfa mycorrhizae indicates that signal transduction pathways used in forming arbuscular mycorrhizae and Rhizobium-induced nodules be conserved. Proc. Natl. Acad. Sci. USA 94:5467-5472.

Vijn, I., Henning, C., Lauridsen, P., Kardasky, I., Quandt, H.-J., Broer, I., Janneke, D., Jensen, E. O., van Kammen, A., and Bisseling, T. 1995a. A $200 \mathrm{bp}$ region of ENOD12 promoter is sufficient for nodule-specific and Nod factor induced expression. Plant Mol. Biol. 28:1103-1110.

Vijn, I., Yang, W. C., Pallisgard, N., Jensen, E. O., van Kammen, A., and Bisseling, T. 1995b. VsENOD5, VsENOD12 and VsENOD40 expression during Rhizobium-induced nodule formation on Vicia sativa roots. Plant Mol. Biol. 28:1111-1119.

Yang, W. C., Katinakis, P., Hendriks, P., de Vries, F., Spee, J., van Kammen, A., Bisseling, T., and Franssen, H. 1993. Characterization of GmENOD40, a gene showing novel patterns of cell-specific expression during soybean nodule development. Plant J. 3:573-585. 